\title{
СТРУКТУРА И ЛЕДНИКОВЫЙ МОРФОГЕНЕЗ ПАНДИВЕРЕСКОЙ ВОЗВЫШЕННОСТИ
}

В последнее время в геологической литературе идет оживленная дискуссия об активном проявлении структур кристаллического фундамента и осадочного чехла в современном рельефе и об их роли в ледниковом морфогенезе. Попытку выяснить роль структур кристаллического фундамента и осадочного чехла в рельефе коренных пород и в формировании ледникового рельефа на примере аккумулятивных островных возвышенностей Южной Эстонии мы уже делали ранее (Вахер и др., 1980). Подробный анализ позволил нам заключить, что неотектонические движения ввиду незначительной . интенсивности и малой амплитуды не могли существенно повлиять на формирование островных аккумулятивных возвышенностей, где мощность четвертичных отложений и скорость аккумуляции в ледниковое время были весьма большими. Ведущую роль в формировании островных аккумулятивных возвышенностей,. несомненно, играла динамика ледника, которая во многом зависела от характера подледниковой поверхности.

В данной статье рассматривается вопрос о роли структур кристаллического фундамента и осадочного чехла в пределах цокольной Пандивереской возвышенности, принципиально отличающейся от островных аккумулятивных возвышенностей и игравшей ведущую роль в гляциодинамике последних этапов деглящиации Северной Прибалтики, а также в зарождении Балтийского моря (Квасов, Раукас, 1970).

Пандивереская возвышенность является самой высокой частью Северной Әстонии (до 166 м, Эмумяги) и характеризуется в целом маломощным (обычно 2-5 м) покровом четвертичных отложений. Абсолютные отметки рельефа коренных пород достигают $120-130$ м, а относительная высота составляет около 60 м. Возвышенность четко выделяется как в современном, так и древнем рельефе, что и послужило основанием для приписывания ей неотектонической активности (Ряхни, 1973 и др.). По мнению Н. И. Николаева (Nikolajev и др., 1967), суммарное поднятие Пандивереской возвышенности в неоген-четвертичное время составляет около 100 м, что, на наш взгляд, сильно преувеличено.

Северо-Восточная Эстония геологически наиболее изученный район республики, где в связи с геологической разведкой на сланцы и фосфориты заложено большое количество буровых скважин. Строение ледниковых отложений в Северной Эстонии, в том числе и на Пандивереской возвышенности, отличается простотой, особенно по сравнению с весьма сложным строением островных аккумулятивных возвышенностей Южной Әстонии (Хаанья, Отепя). Учитывая вышесказанное, мы имеем благоприятные условия для выявления структур и установления генезиса коренной, а также ледникового морфогенеза Пандивереской возвышенности.

Поверхность коренных пород на Пандивереской возвышенности изобилует трещинами, направление которых преимущественно северо- 
западное или северо-восточное. Наличие трещин способствовало широкому развитию карста. В кристаллическом фундаменте возвышенности, по всей вероятности, имеется ряд разломов и блоков разного ранга (Побул, Сильдвээ, 1973), которые образовались, видимо, еще в протерозое. Ю. Хейнсалу и Х. Сильдвээ (1971) выделяют в кристаллическом фундаменте и осадочном чехле неотектонически активный Тапаский блок, с которым в настоящее время как будто тоже связаны дифференцированные тектонические движения. В пользу активности этого блока, по их мнению, говорят данные повторного нивелирования трасс, пересекающих разломы, ограничивающие Тапаский блок. К границам Тапаского блока приурочены участки резких изменений скорости вертикальных движений. Но Тапаский, как и другие давно отмершие блоки, отнюдь не совпадает в плане с расположением Пандивереской возвышенности (рис. 1) и поэтому не позволяет расшифровать генезис возвышенности в целом.

В трещиноватых коренных породах Пандивереской возвышенности установлены секущие сбросы и флексуры, амплитуда которых невелика. Так, в пределах Азериского нарушения амплитуда смещения по подошве кукрузеского горизонта достигает 26 м (Вахер, 1983), а в пределах Вийтнаского - 22 м. В пределах других нарушений (Рахклаское и др.) амплитуды смещений еще меньше.

Для выявления влияния древних структур на современный рельеф возвышенности по густой сети разведочных скважин нами были составлены меридиональные и широтные геологические профили. На рис. 2 видно, что в осадочном чехле возвышенности имеются 3 зоны нарушений, в пределах которых амплитуда смещения по подошве кукрузеского горизонта в данном разрезе составляет (соответственно с запада на восток): I - Вийтнаское - 22; II - Азериское - 11; III - Рахклаское - 12 м. Маркирующие поверхности кукрузеского и раквереского горизонтов в западной части возвышенности находятся примерно на 8 м ниже, нежели в восточной части. В центральной части возвышенности абсолютные отметки коренных пород и современного рельефа наивысшие, но в осадочном чехле никакого поднятия не наблюдается.

Сквозные линейные дислокации Северо-Восточной Әстонии развивались длительное время, в течение не менее чем двух тектонических этапов - байкальского и послеордовикского (позднекаледонского?), но интенсивность их развития изменялась во времени (Вахер и др., 1980). Байкальский этап отличается слабым развитием линейных структур на вендском подэтапе и усилением интенсивности их формирования на раннекембрийском подэтапе. Амплитуды послеордовикских подвижек составляли примерно $50 \%$ современной амплитуды поднятия фундамента. Всем этим линейным нарушениям, кроме Вийвиконнаской зоны (Вахер, 1983), расположенной восточнее Пандивереской возвышенности, характерна пассивность в новейшее время.

Густая сеть скважин на детально разведанной площади Әстонского месторождения горючих сланцев и точность определения абсолютных высот поверхности коренных пород позволяют провести изогипсы в этом районе по меньшей мере через каждый метр. Но и при такой детальности изображения, указанные нарушения (например, в виде складок: таблица, 1) в рельефе коренных пород не проявляются (Вахер, Таваст, 1979). Если они и оживились в новейшее время, то настолько слабо, что не были в состоянии заметно преобразовать денудационную поверхность коренных пород.

Таким образом, сравнительный анализ расположения блоков кристаллического фундамента, структур осадочного чехла и рельефа коренных пород не подтверждает наличия приподнятого блока, соответствующего Пандивереской возвышенности. Следовательно, ведущую 


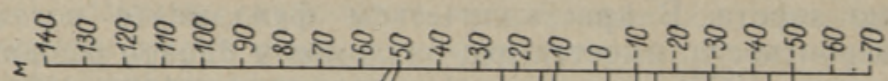

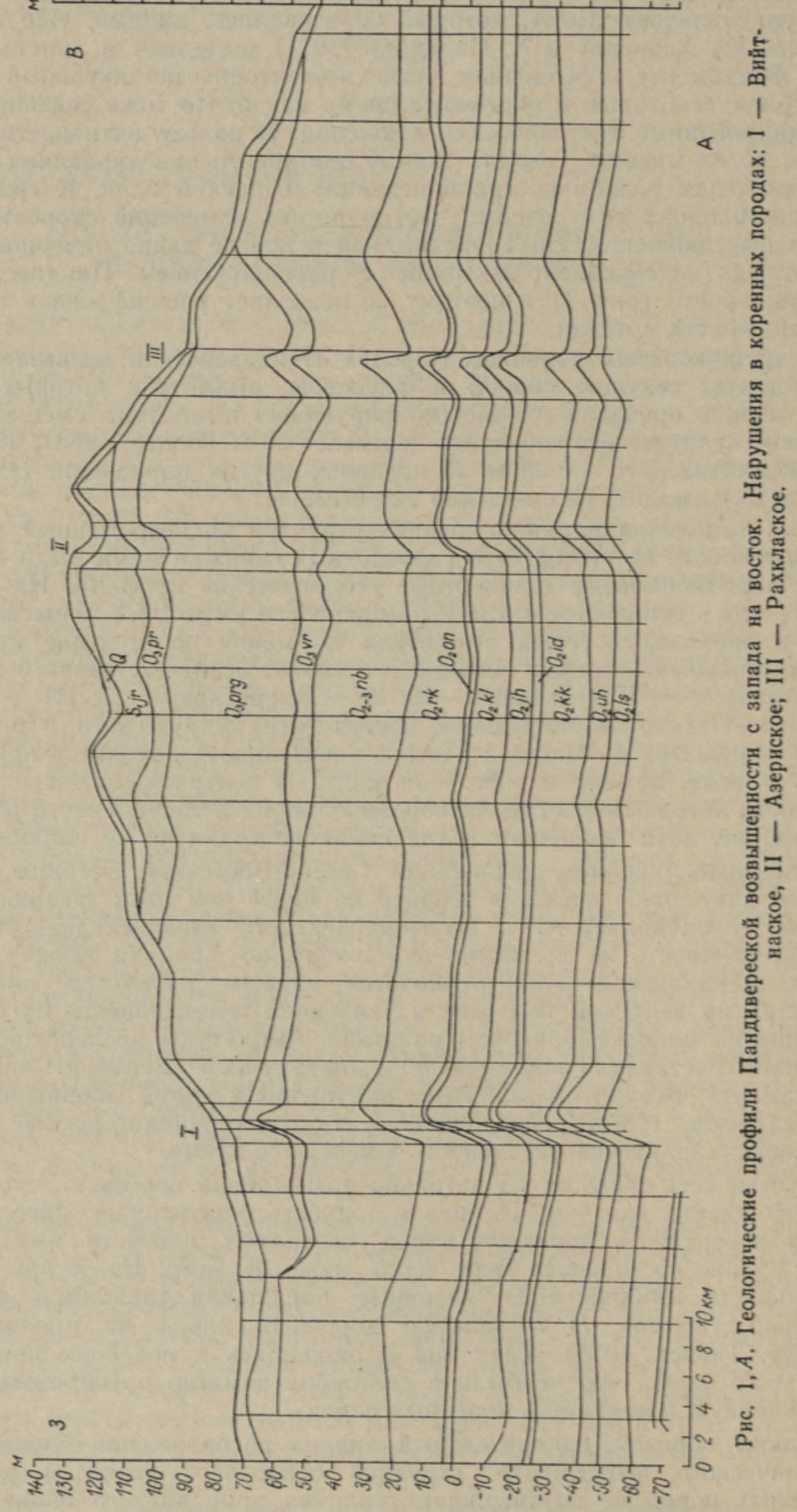




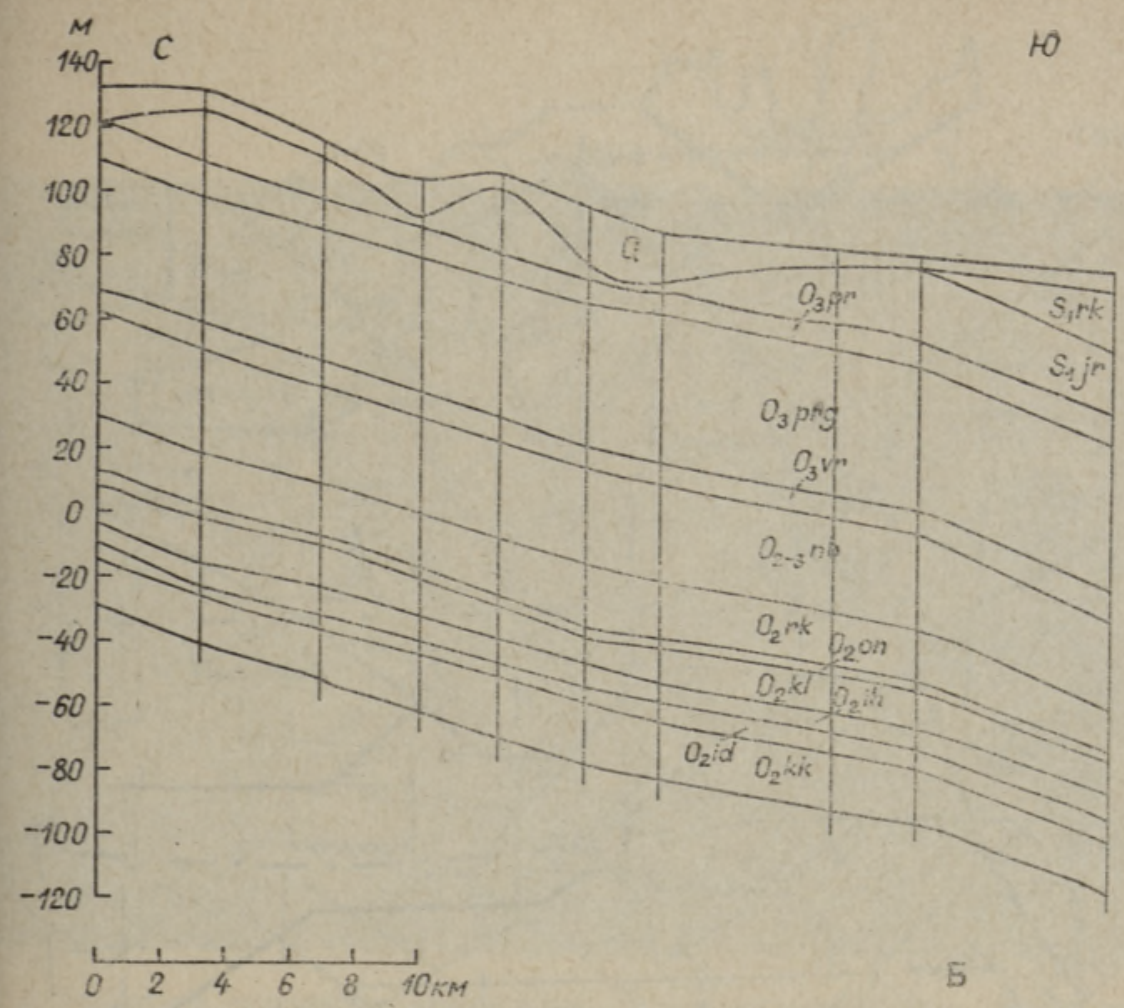

Рис. 1, Б. Геологические профили Пандивереской возвышенности с севера на юг. Расположение профилей см. на рис. 3 .

роль при морфологическом обособлении коренной возвышенности играли экзогенные процессы, в частности селективная дочетвертичная денудация и плейстоценовая экзарация. Голоценовые геологические процессы изменили общий вид коренного рельефа возвышенности значительно меньше.

Учитывая сказанное, совершенно необосновано изображение Пандивереской возвышенности в качестве неотектонически активного поднятия на Неотектонической карте республик Советской Прибалтики (1982).

Ледниковый рельеф Пандивереской возвышенности хорошо изучен и подробно описан во многих легко доступных публикациях (Rähni, 1961; Ряхни, 1961; Раукас и др., 1971; и др.) и поэтому нет необходимости повторяться. Напомним только, что структурный план (расположение форм рельефа и их комплексов) ледникового рельефа цокольной возвышенности четко отличается от структурного плана рельефа островных возвышенностей (Хаанья, Отепя) и таких гляциодепрессий как Западно-Эстонская низина (Карукяпп, 1979). По составленным роз-диаграммам ориентировки ледниковых форм рельефа, на Пандивереской возвышенности всюду преобладают радиальные элементы ледникового рельефа, но на цокольных возвышенностях радиальные элементы проявляются особенно четко потому, что маргинальные формы ледникового рельефа здесь крайне редки.

Известно, что реки и палеоврезы на Пандивереской возвышенности наследуют в основном трещины северо-западного направления (Мийдел, 1971; Таваст, Раукас, 1982). В связи с этим мы задались целью оценить также степень связи между радиальными ледниковыми фор- 


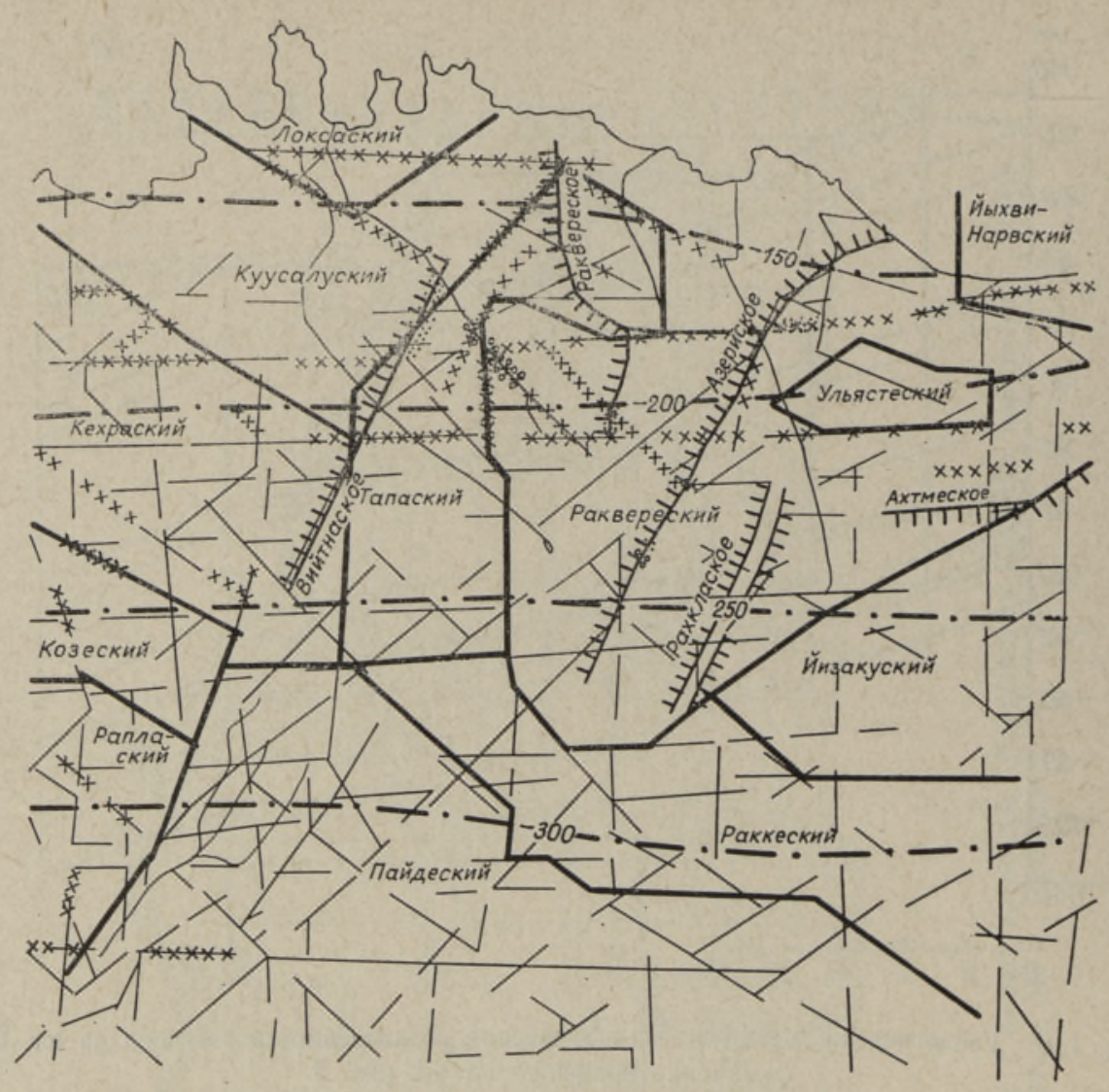

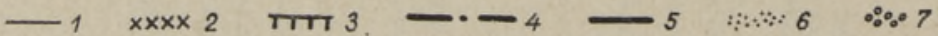

Рис. 2. Схема сопоставления структур кристаллического фундамента (Побул, Сильдвеэ, 1973), коренных пород (Вахер, 1983) и ледникового рельефа. 1 - разрывные нарушения в кристаллическом фундаменте, по данным магннторазведки, 2 - по данным гравиразведки; 3 - тектонические нарушения в коренных породах; 4 - изогипсы рельефа фундамента; 5 - границы блоков в фундаменте; 6 - ледниковые формы рельефа, совпадающие с нарушениями; 7 - совпадающие с древними долинами.

мами рельефа и структурами кристаллического фундамента и осадочного чехла, используя для этого карты их расположения (рис. 2). Выяснилось, что только отдельные формы ледникового рельефа (Вийтнаский ледниковый комплекс и др.) имеют некоторую связь со структурными элементами фундамента и осадочного чехла. Таким образом, преимущественно радиальное расположение здешних ледниковых форм отражает прежде всего характер и динамику отступления материкового льда.

Во время последнего оледенения Пандивереская возвышенность была звеном ледораздельной зоны между Балтийским и Финляндским ледниковыми потоками. Во время максимального распространения валдайского ледника возвышенность была расположена в краевой части центрального ледникового щита и была приурочена к зоне интенсивной экзарации, по-видимому, несколько меньшей, нежели в соседних гляциодепрессиях.

В ледниковом морфогенезе Пандивереской возвышенности и соседних гляциодепрессий в поздневалдайское время можно выделить три этапа (рис. 3). 

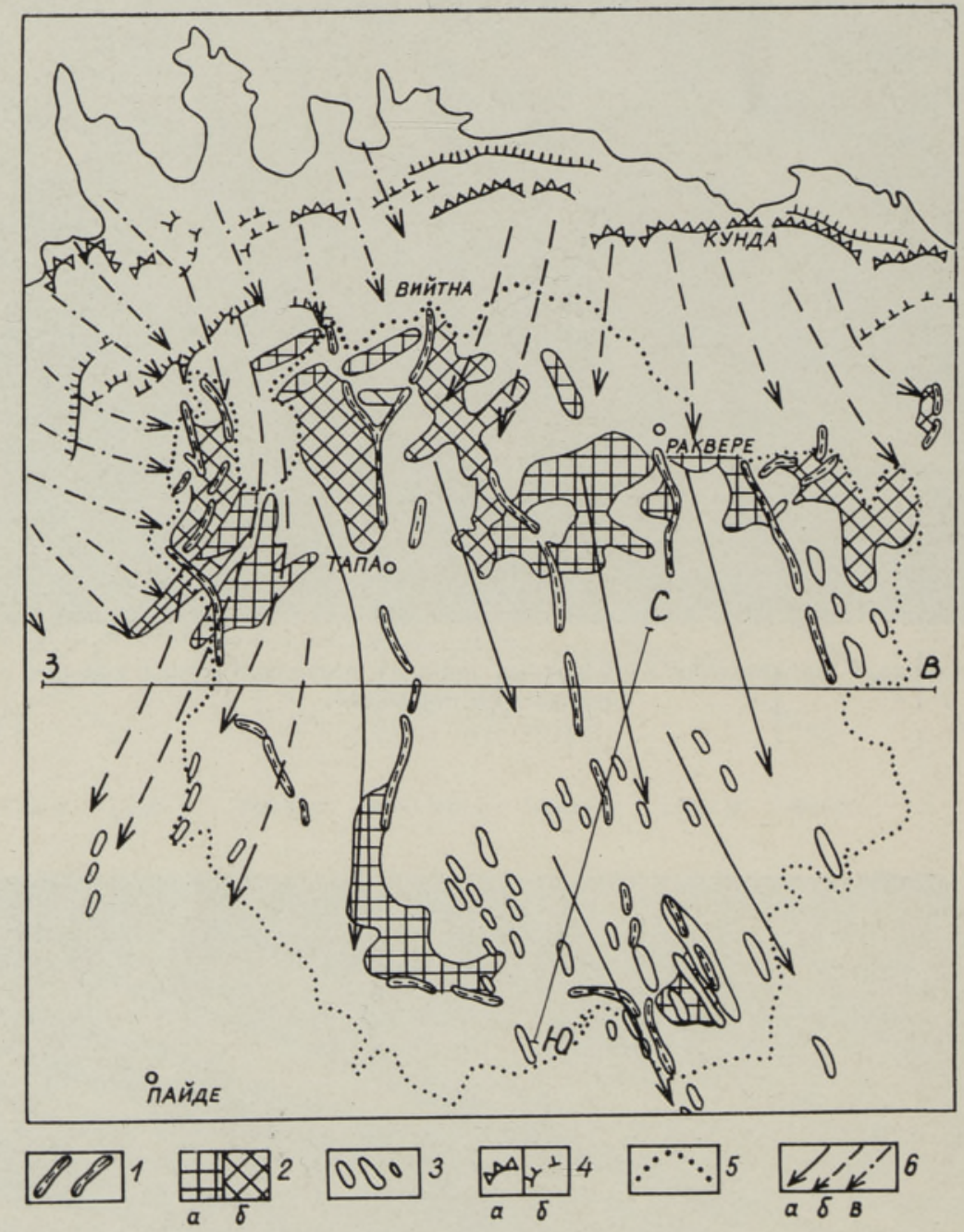

Рис. 3. Гляциодинамическая схема формирования Пандивереской возвышенности. 1 - радиальные озы; $2 a-$ холмисто-моренный рельеф, 26 - камовый рельеф; 3 друмлины; $4 a-$ глинт, $46-$ уступ в четвертичных отложениях; 5 - граница Пандивереской возвышенности; 6 - направление движения ледника во время формирования: $a$ - Саадъярвского друмлинного поля, б - Тюриского друмлинного поля, в - Раазикуских друмлин. Месторасположение геологических разрезов С - Ю и $3-\mathrm{B}$, приведенных на рис. 1. 
рое к северо-западу от возвышенности достигает $55-57$ м, а в центральной части возвышенности составляет $44-45$ м, т. е. склон возвышенности в сторону ледника в конце оледенения был более высоким, чем в настоящее время. Низкий уровень талых вод во льду, обусловленный характером подледникового рельефа и большое содержание морены в мертвом льду способствовали сохранению льда на возвышенности. В ходе отступления Западно-Пандивереского языка к краю ледника подступили подпруженные ледниковые воды, благодаря высокому уровню которых он быстро оттаял. Из-за разницы в высотах потоки талых вод с северной части возвышенности могли направиться только на север.

По мере отступления ледника понизился уровень приледникового водоема, в который по древним долинам стекали флювиогляциальные потоки с Пандивереской возвышенности, образуя ясно выраженные флювиогляциальные дельты на абсолютных отметках $45-48$ м с наклоном фронтальных слоев около $20-25^{\circ}$ на север (таблица, 2). Флювиогляциальные потоки, направлением с юга на север, встречались также в других местах Северной Әстонии (Кунда), о чем свидетельствует характер слонстости.

Флювиогляциальные дельты севернее Пандивереской возвышенности на современном уровне $45-48$ м образовались, по всей вероятности, до паливереской стадии в начале аллереда около $11300-$ 11000 л.н.

Когда окончательно растаял мертвый лед, кончился этап гляциоморфогенеза Пандивереской возвышенности. Влияние ледника паливереской стадии на Пандиверескую возвышенность ограничивается только воздействием озерно-ледниковых бассейнов на ее склоны.

\section{Выводы}

1. Имеющиеся данные о структуре Пандивереской возвышенности не подтверждают мнения об ее интенсивном неотектоническом поднятии относительно окружающей территории, т. е. происхождение возвышенности денудационно-экзарационное. В поздне- и послеледниковое время Пандивереская возвышенность поднималась вместе с окружающими районами Виру-Харьюского плато как часть последнего.

2. Зоны разломов и нарушений в фундаменте и в осадочном чехле, как правило, не совпадают с ледниковыми формами рельефа. В связи с этим тектоническая активность, на наш взгляд, существенно не повлияла на ледниковый морфогенез.

3. Неравномерное гляциоизостатическое поднятие в поздне- и послеледниковое время в районе Пандивереской возвышенности предопределило развитие позднеледниковых бассейнов и высо́ты древних денудационных поверхностей.

Чтобы иметь верное представление о ледниковом морфогенезе, необходимо восстановить реальные высотные соотношения отдельных палеоповерхностей, т. е. учесть характер и амплитуду неравномерного поздне- и послеледникового гляциоизостатического поднятия земной коры в каждом конкретном районе и пункте, что в значительной мере изменит прежние взгляды о ледниковом морфогенезе возвышенности.

\section{Л И Т Е Р А Т У Р А}

Bахер P. М. Тектоника фосфоритно-сланцевого бассейна Северо-Восточной Эстонии. Автореф. канд. дис. Минск, 1983. 
Baxep P. М., Раукас А. В., Таваст Э. Х. О роли тектонических движений и подстилающей поверхности в формировании островных возвышенностей Эстонии. - Геоморфология, $1980,3,55-65$.

Baxep P. М., Таваст Э. Х. Вопросы формирования рельефа коренных пород Эстонии. - В сб.: Проблемы унаследованности тектонических структур в Прибалтике и Белоруссии. Таллин, 1979, 92-102.

Kарукяпn P. Я. Особенности формирования четвертичного покрова и форм рельефа в готигляциальном этапе дегляциации (на примере территории Эстонии). Автореф. канд. дис. Вильнюс, 1979.

Квасов Д. Д., Раукас А. В. О позднеледниковой исторни Финского залива. - Изв. Всесоюз. географ. об-ва, 1970, вып. 5, 102, 432-438.

Мийдел A. Новые данные о связи между направлениями долин и тектонической трещиноватостью в Северной Әстонии. - Изв. АН ЭССР. Хнм. Геол., 1971, 20, $160-162$.

Неотектоническая карта республик советской Прибалтики. Масштаб 1:500000. Л., 1982.

Побул Э., Сильдвээ Х. О разрывных нарушениях кристаллического фундамента Эстонии. - Изв. АН ЭССР. Хим. Геол., 1973, 22, 51-57.

Раукас А. В., Ряхни Э. Э., Мийдел А. М. Краевые ледниковые образования Северной Эстонин. Таллин, 1971.

Ряхни Э. Краевые образования последнего оледенения в Северной Эстонии (тезнсы доклада). Таллин, 1961, 21-23.

Таваст Э., Раукас А. Рельеф коренных пород Эстонин. Таллин, 1982.

Хейнсалу Ю., Сильдвеэ Х. О связях между неотектоническими и современными дифференцированными движениями и зонами разломов в Северо-Восточной Әстонин. - Изв. АН ЭССР. Хнм. Геол., 1971, 20, 260-266.

Nikolajev, N. I., Babak, V. I., Medyantsev, A. I. Some neotectonic problems of the Baltic shield and the Norwegian Caledonides. Baltica, 3. Vilnius, 1967, 183207.

Rähni, E. Viimase mandrijää servamoodustistest Pandivere kõrgustikul. - ENSV TA Geol. Inst. Uurimused, VII. Tallinn, 1961, 47-54.
Ннститут геологии
Академии наук Эстонской ССР
Поступила в редакцию
11/III 1984

R. KARUKAPP, E. TAVAST

\section{PANDIVERE KORGUSTIKU GEOLOOGILINE STRUKTUUR JA LIUSTIKULINE MORFOGENEES}

Pōhja- ja Kirde-Eesti rikkaliku geoloogilise uurimismaterjali analüüsi pōhjal on võimalik väita, et seisukoht Pandivere kōrgustiku intensiivse kerkimise kohta Pöhja-Eesti lavamaa suhtes pole põhjendatud, s. t. kōrgustik on peamiselt denudatsioonilis-eksaratsioonilise päritoluga ning tektoonika osa kõrgustiku kujunemisel on teisejärguline. Hilisjääajal ja jääajajärgsel ajal allus kōrgustik kui Põhja-Eesti lavamaa osa glatsioisostaatilisele kerkele.

Alus- ja pealiskorra rikete ja lōhede vööndid ei lange üldiselt kokku liustikutekkeliste pinnavormidega. Selle alusel on väidetud, et neotektoonilised protsessid ei mōjutanud oluliselt liustikulise pinnamoe kujunemist hilisjääajal.

R. KARUKAPP, E. TAVAST

\section{TECTONIC STRUCTURE AND GLACIAL MORPHOGENESIS OF PANDIVERE UPLAND}

In the Late- and Post-Glacial time Pandivere Upland, of denudational and exarational origin, reveals a glacioisostatic uplift as a part of the North Estonian plateau, without blockwise movements.

The neotectonic movements did not influence the glacial processes of morphogenesis, and therefore, as a rule, the glacial relief forms do not follow the destruction zones of bedrock or basement (Fig. 2). 